\title{
Social participation and perceived depression among elderly population in South Africa
}

\author{
This article was published in the following Dove Press journal: \\ Clinical Interventions in Aging \\ 23 June 2017 \\ Number of times this article has been viewed
}

\author{
Gang Hao' \\ Ghose Bishwajit ${ }^{2}$ \\ Shangfeng Tang ${ }^{2}$ \\ Changping $\mathrm{Nie}^{1}$ \\ Lu Ji ${ }^{3}$ \\ Rui Huang ${ }^{4}$ \\ 'Zunyi Medical and Pharmaceutical \\ College, Zunyi, ${ }^{2}$ School of Medicine \\ and Health Management, Tongji \\ Medical College, Huazhong University \\ of Science and Technology, Wuhan, \\ ${ }^{3}$ Cancer Center, Sun Yat-Sen \\ University, Guangzhou, Guangdong, \\ ${ }^{4}$ School of Pharmacy, Tongji Medical \\ College, Huazhong University of \\ Science and Technology, Wuhan, \\ People's Republic of China
}

\begin{abstract}
There is a growing consensus regarding the influence of various psychosocial factors such as degree of social participation on health and disease outcomes, quality of life, and general well-being. Older individuals with diminished motor and physical functionality suffer a heightened risk of social exclusion and loneliness. Previous studies have demonstrated the association between social exclusion and loneliness with mental health among the older population. In the present study, we aimed to investigate whether or not difficulty in social participation has any relationship with perceived depression among older individuals in South Africa. We collected cross-sectional data from the SAGE Well-Being of Older People Study 2010 on 422 men and women aged 50 years and above. Perceived depression and loss of interest in things (eg, personal relationships, hobbies) during the last 12 months were used as outcome variables with difficulty in joining community activities, relationships/community participation, friendships, and visiting family/friends as the main explanatory variables. Findings indicated that the prevalence of self-reported depression and the feeling of reduced interest in most things were respectively $51.9 \%$ and $43.8 \%$. In the multivariate analysis, those who reported difficulty in joining community activities had respectively $64 \%(\mathrm{OR}=1.639 ; 95 \% \mathrm{CI}=1.081-2.583)$ and $69 \%$ (OR $=1.685 ; 95 \% \mathrm{CI})$ higher odds of depression and loss of interest in things compared with those who did not report any difficulty. The study concludes that addressing the barriers to engaging in community activities may help minimize burden of depression among the elderly population in South Africa. Furthermore, large-scale studies are warranted to explore the social and structural barriers which constrain community participation among the elderly population.

Keywords: depression, elderly population, social participation, South Africa, well-being of older people study
\end{abstract}

\section{Introduction}

With the growing understanding of the role of social determinants of health, general well-being, and quality of life (QoL), the concept of social cohesion and/or participation has been a recurring theme among policy makers and researchers across a wide range of disciplines such as political science, population health, and social psychology to name a few. In public health literature, the concept has been used extensively since the introduction of the International Classification of Functioning, Disability and Health by the World Health Organization (WHO) in 2001. ${ }^{1}$ Despite this widespread use, there remains a lack of universally agreed definition of social participation, and hence clarification is required for appropriate contextual application of the term. From the perspective of civil society organizations, social participation can indicate the involvement of the general public in health decision-making as an essential element of democratic decision-making process health care. ${ }^{2,3}$ On the other hand, from the social capital perspective it can refer to the interconnectivity and/or cohesiveness
Correspondence: Shangfeng Tang School of Medicine and Health Management, Tongji Medical College, Huazhong University of Science and Technology, I 3 Hangkong Road, Wuhan, Hubei 430030, People's Republic of China Tel +86 I3349895639

Email sftang@hust.edu.cn 
of the members in a given society in terms of interpersonal relationships. ${ }^{4,5}$ The focus of the present study was to explore the relationship between interpersonal/social participation in the context of mental health outcomes among elderly men and women in South Africa.

Social participation, as opposed to social exclusion/ isolation, has been identified as an important social determinant of health. ${ }^{6}$ With advancing age, people find it increasingly hard to maintain active social networks, maintain existing relationships, and to initiate new relationships. ${ }^{7}$ Older people most often lack the opportunity to engage in social activities owing to diminished physical and motor functionality, and thus are subjected to greater exposure to loneliness and isolation, which in turn are associated with depression and cognitive disorders. ${ }^{6,8}$ Conversely, depression itself can affect the capacity to effectively fulfill one's social roles, and can exert significant impact on perceived health, social well-being (SWB), and cause loss of interest in life at large. ${ }^{9}$ With the expanding proportion of the elderly population worldwide, addressing the social determinants of depression is therefore essential for promoting social health, QoL, and SWB among the elderly population. Evidently, research evidence in the context of developing countries is limited, which consequently prevents informed policy making to address the underlying health and social issues, especially the ones unique to the local sociocultural environment. Given the multifactorial etiology of depression, the distribution of the environmental, physical, and social risk factors (the biopsychosocial model) are expected to vary substantially between developed and developing countries. Thus, the association between social participation and depression observed in a certain setting (and age group) may not hold true for another. Therefore, in the present study we aimed to examine whether or not social participation was associated with perceived depression among older people in South Africa.

\section{Materials and methods Data collection}

This study was based on secondary data obtained from South Africa - SAGE Well-Being of Older People Study (WOPS) 2010 Wave 1 . The WOPS 2010 is a household health survey and was designed and implemented by the WHO and the Africa Centre for Health and Population Studies. ${ }^{10}$ The main objective of the survey was to describe the effects on physical and mental health across various chronic diseases as well as social situation among older people infected and/or affected by HIV. Face-to-face interviews were carried out between March to August 2010 on a sample of 422 men and women aged 50 years within the Africa Centre surveillance area. Details of sampling procedures and study protocols were published elsewhere..$^{10,11}$

\section{Variables}

The two outcome measures of this study were: 1) perceived depression, and 2) feeling of lack of interest in things. Participants were asked: "During the last 12 months, have you had a period lasting several days when you felt sad, empty or depressed?" and, "During the last 12 months, have you had a period lasting several days when you lost interest in most things you usually enjoy such as personal relationships, work or hobbies/recreation?" with "Yes" and "No" options as answers to both questions.

The main explanatory variables were perceived difficulty in maintaining social participation and relationships. The following options were selected from the WOPS questionnaire based on their relevance to the theme of the study:

1) difficulty in relationships/community participation;

2) difficulty experienced in friendships;

3) difficulty joining community activities;

4) difficulty visiting family/friends.

In order to adjust the analysis on the association between the outcome and explanatory variables, the following were included as potential confounders: age (50-59, 60-69, 70-79, 79+ years), sex (female, male), marital status (married, divorced/widowed, never married), educational attainment (nil, adult education only, up to grade 12), financial situation compared to 3 years ago (better, about the same, much worse), current tobacco use habit (daily, not daily, no), alcohol consumption during the last 12 months (less than once a month, 1-7 days/month, 1-4 days or higher/week, no), satisfaction with self (very satisfied, satisfied, neither satisfied nor dissatisfied, dissatisfied, very dissatisfied).

Financial situation compared to 3 years ago was used as a proxy measure of economic status as no direct information about individual income was available. Tobacco and alcohol consumption have been shown to be associated with depression, and hence were considered for inclusion along with the other sociodemographic variables. Satisfaction with self was also considered for this study as it is likely to vary according to one's physical and mental health status, and thus can reflect the individual's life satisfaction and sense of well-being to a certain degree.

\section{Data analysis}

In total 422 men and women aged $\geq 50$ years, regardless of their HIV status were included in the analysis. The first step 
of the analysis was descriptive statistics to present the basic characteristics of the study population. A contingency table was generated to facilitate the comparison of the prevalence of subjects who reported depression and loss of interest across the sociodemographic variables. Chi-square tests were used to calculate the $P$-values of the bivariate associations. In addition, two multivariate models were run for two outcome variables to calculate the association adjusted for the confounders. The results of regression analysis were presented as ORs. Besides ORs, 95\% CIs were also reported to check the precision of the calculations. A two-tailed $P$-value of $<0.05$ was set as level of significance for all calculations. All analyses were carried out using $\mathrm{R}$ statistical software.

\section{Ethics statement}

The WOPS survey was approved by the Research Ethics Committee of the University of KwaZulu-Natal. Informed written consent was obtained from all WOPS participants prior to the interviews. The dataset has been made available in the public domain in anonymized form, hence no further approval was necessary for this study.

\section{Result}

\section{Prevalence rates and participant characteristics}

Table 1 indicates that the prevalence of self-reported depression during the last 12 months was $51.9 \%$, and that having a

Table I Basic characteristics of the sample population $(n=422)$ WOPS 2010

\begin{tabular}{|c|c|c|c|}
\hline Characteristics & $\mathbf{N}(\%)$ & $\begin{array}{l}\text { Felt sad, empty } \\
\text { or depressed } \\
\text { in the last } \\
\text { I } 2 \text { months } \\
(51.9 \%)\end{array}$ & $\begin{array}{l}\text { Lost interest } \\
\text { in most things } \\
\text { in the last } \\
12 \text { months } \\
(43.8 \%)\end{array}$ \\
\hline \multicolumn{4}{|l|}{ Age (years) } \\
\hline $50-59$ & $193(45.7)$ & 44.3 & 47.6 \\
\hline $60-69$ & $129(30.6)$ & 29.7 & 25.4 \\
\hline $70-79$ & $70(16.6)$ & 16.9 & 18.4 \\
\hline $79+$ & $30(7.1)$ & 9.1 & 8.6 \\
\hline$P$-value & & 0.396 & 0.183 \\
\hline \multicolumn{4}{|l|}{ Sex } \\
\hline Female & $316(74.9)$ & 81.7 & 80.0 \\
\hline Male & $106(25.1)$ & 18.3 & 20.0 \\
\hline$P$-value & & 0.001 & 0.041 \\
\hline \multicolumn{4}{|l|}{ Marital status } \\
\hline Married & $116(27.5)$ & 28.3 & 29.7 \\
\hline Divorced/widowed & $210(49.8)$ & 36.1 & 41.6 \\
\hline Never married & $96(22.7)$ & 35.6 & 28.6 \\
\hline$P$-value & & 0.001 & 0.007 \\
\hline
\end{tabular}

Table I (Continued)

\begin{tabular}{|c|c|c|c|}
\hline Characteristics & $\mathbf{N}(\%)$ & $\begin{array}{l}\text { Felt sad, empty } \\
\text { or depressed } \\
\text { in the last } \\
\text { I } 2 \text { months } \\
(51.9 \%)\end{array}$ & $\begin{array}{l}\text { Lost interest } \\
\text { in most things } \\
\text { in the last } \\
12 \text { months } \\
(43.8 \%)\end{array}$ \\
\hline \multicolumn{4}{|l|}{ Educational attainment } \\
\hline Nil & $174(4 \mid .2)$ & 49.9 & 48.6 \\
\hline $\begin{array}{l}\text { Adult education } \\
\text { only }\end{array}$ & $27(6.4)$ & 2.8 & 3.2 \\
\hline Up to grade 12 & $221(52.4)$ & 47.3 & 48.1 \\
\hline$P$-value & & 0.018 & 0.005 \\
\hline \multicolumn{4}{|c|}{ Financial situation compared to 3 years ago } \\
\hline Better & $67(15.9)$ & 9.6 & 12.4 \\
\hline About the same & $136(32.2)$ & 29.2 & 28.6 \\
\hline \multirow[t]{2}{*}{ Much worse } & $219(51.9)$ & 61.2 & 58.9 \\
\hline & & 0.023 & 0.004 \\
\hline \multicolumn{4}{|l|}{ Current tobacco use } \\
\hline Daily & $33(7.8)$ & 8.2 & 9.7 \\
\hline Not daily & $15(3.6)$ & 2.7 & 3.8 \\
\hline No & $374(88.6)$ & 89.1 & 86.5 \\
\hline$P$-value & & 0.806 & 0.605 \\
\hline \multicolumn{4}{|c|}{ Average alcoholic consumption in the last 12 months } \\
\hline$<$ once a month & $23(5.5)$ & 7.3 & 7.0 \\
\hline I to 7 days/month & $21(5.0)$ & 4.1 & 4.3 \\
\hline I to 4 days/week & $13(3.1)$ & 4.1 & 2.2 \\
\hline No & $365(86.5)$ & 84.5 & 86.5 \\
\hline$P$-value & & 0.301 & 0.443 \\
\hline \multicolumn{4}{|l|}{ Satisfaction with self } \\
\hline Very satisfied & $8(1.9)$ & 0.5 & 0.5 \\
\hline Satisfied & $270(64.0)$ & 48.4 & 48.6 \\
\hline $\begin{array}{l}\text { Neither satisfied } \\
\text { not dissatisfied }\end{array}$ & $85(20.1)$ & 26.5 & 24.3 \\
\hline Dissatisfied & $54(12.8)$ & 22.4 & 24.3 \\
\hline Very dissatisfied & $5(1.2)$ & 2.3 & 2.2 \\
\hline$P$-value & & $<0.0001$ & $<0.0001$ \\
\hline \multicolumn{4}{|c|}{ Difficulty joining community activities } \\
\hline No & $210(49.8)$ & 45.7 & 41.1 \\
\hline Yes & $212(50.2)$ & 54.3 & 58.9 \\
\hline$P$-value & & 0.032 & 0.001 \\
\hline \multicolumn{4}{|c|}{ Difficulty in relationships/community participation } \\
\hline No & II $4(27.0)$ & 26.0 & 27.6 \\
\hline Yes & $308(73.0)$ & 74.0 & 72.4 \\
\hline$P$-value & & 0.218 & 0.153 \\
\hline \multicolumn{4}{|c|}{ Difficulty experienced in friendships } \\
\hline No & $75(17.8)$ & 17.4 & 18.4 \\
\hline Yes & $347(82.2)$ & 82.6 & 81.6 \\
\hline$P$-value & & 0.157 & 0.035 \\
\hline \multicolumn{4}{|c|}{ Difficulty visiting family/friends } \\
\hline No & $116(27.5)$ & 29.7 & 28.6 \\
\hline Yes & $306(72.5)$ & 70.3 & 71.4 \\
\hline$P$-value & & 0.174 & 0.08 \\
\hline
\end{tabular}

Note: $P$-value calculated from chi-square bivariate test.

Abbreviation: WOPS, Well-Being of Older People Study.

feeling of reduced interest in most things was $43.8 \%$ during the same time.

Basic sociodemographic characteristics were also presented in Table 1. Mean age of the respondents was 
$62.27( \pm 10.09)$, and most of them were 50-59 years of age (45.7\%). Of the 422 participants, approximately three quarters were female (74.9\%). Approximately half were widowed/ divorced, and more than a quarter were currently married (27.5\%). More than two-fifths had no formal education (41.2\%), and more than half had grade 12 level qualification. Regarding economic situation, $51.9 \%$ of the participants reported having worse conditions compared to 3 years ago. Prevalence of daily smoking was $7.8 \%$, and that of occasional smoking was $3.6 \%$. Prevalence of drinking was about the same as $86.5 \%$ reported never drinking compared to $88.6 \%$ who reported never smoking. The majority of the participants expressed satisfaction about self (64\%), while $12.8 \%$ and $1.2 \%$ reported being dissatisfied and very dissatisfied respectively.

Almost half reported $(49.8 \%)$ difficulty in joining community activities and approximately three quarters (73\%) experienced difficulty in maintaining relationships/ community participation, while more than four fifths experienced difficulty in friendships $(82.2 \%)$ and close to three quarters $(72.5 \%)$ in visiting family/friends.

Results of bivariate test indicated that depression was more likely to be reported by those who were female, divorced/widowed, had no formal education, experienced worsening of economic situation compared to 3 years ago, and were satisfied with their health. Regarding social participation indicators, only having difficulty joining community activities showed a significant association with both perceived depression and loss of interest.

Results of multivariate analysis were presented in Table 2. As observed in the bivariate test, perceived depression and loss of interest appeared to be associated with having difficulty joining community activities only. Those who

Table 2 Multivariate association between difficulty in various social participation/activities and perceived depression among elderly population in South Africa (WOPS 2010)

\begin{tabular}{|c|c|c|}
\hline $\begin{array}{l}\text { Difficulty in } \\
\text { various social } \\
\text { participation/ } \\
\text { activities }\end{array}$ & $\begin{array}{l}\text { Felt sad, empty or } \\
\text { depressed }\end{array}$ & $\begin{array}{l}\text { Lost interest in most } \\
\text { things in the last } \\
12 \text { months }\end{array}$ \\
\hline \multicolumn{3}{|c|}{ Difficulty in relationships/community participation (no) } \\
\hline Yes & $0.762(0.36|-| .215)$ & $0.657(0.354-1.220)$ \\
\hline \multicolumn{3}{|c|}{ Difficulty joining community activities (no) } \\
\hline Yes & $1.639(1.08 \mathrm{I}-2.583)$ & $1.685(1.074-2.788)$ \\
\hline \multicolumn{3}{|c|}{ Difficulty experienced in friendships (no) } \\
\hline Yes & $0.778(0.404-1.498)$ & $0.721(0.367-1.419)$ \\
\hline \multicolumn{3}{|c|}{ Difficulty visiting family/friends (no) } \\
\hline Yes & $1.379(0.897-2.120)$ & $1.002(0.648-1.549)$ \\
\hline
\end{tabular}

Notes: $(\mathrm{no})=$ reference category. Regression models were adjusted for sex, educational status, change in financial situation, and satisfaction with self. Data in bold indicates statistical significance at $P<0.05$.

Abbreviation: WOPS, Well-Being of Older People Study. reported difficulty in joining community activities had respectively $64 \%(\mathrm{OR}=1.639 ; 95 \% \mathrm{CI}=1.081-2.583)$ and $69 \%$ (OR $=1.685 ; 95 \% \mathrm{CI}=1.074-2.788)$ higher odds of reporting depression and loss of interest in things.

\section{Discussion}

This study was carried out to measure the prevalence of perceived depression and loss of interest in pleasurable activities, and to analyze the association between these two with self-reported difficulty in maintaining social participation/relationships in an elderly population sample in South Africa. The analysis was based on secondary data from the WOPS Wave 1. The findings indicated that the prevalence of both perceived depression and of loss of interest was considerably high among the participants. Contrary to expectation, the prevalence was highest among the youngest age group (50-59). This is perhaps because the older individuals have experienced depression for an extended period of time, and/or consider it as a natural outcome due to older age. Noticeable differences in the prevalence rates were observed across sex as well. The crude percentage reporting depression was almost four times as high among women compared with their male counterparts. A similar pattern was observed for reporting loss of interest in things as well. The analysis does not provide any insight on this strikingly high variation, however past researchers also reported a higher prevalence of depression among women as the female:male ratio of global disability from major depression stands at 1.7:1. ${ }^{12}$ Another possible explanation might be the higher rate of reporting difficulty in social participation indicators used in this study (result not shown). Intuitively, individuals with advanced age, regardless of sex, are more likely to experience solitude owing to gradually declining capacity for active participation in community activities, and hence are more likely to suffer episodes of depression and lack of interest in daily life activities.

As expected, marital status appeared to have an important influence on depression and feeling of lack of interest in activities. The percentage of depression was higher among participants who were divorced/widowed and never married compared with those who were currently married. Clearly, elderly couples who might otherwise experience reduced social engagement can enjoy mutual accompaniment in daily activities and have support during times of emotional isolation. Thus, continued marital status can serve as a buffering agent in late-life social exclusion, and as an important indicator in the epidemiology of psychiatric disorders. ${ }^{13}$ In a Swedish study, men and women who were divorced/unmarried were found to have an increased mortality risk even after adjusting 
for social class, which indicates an overall positive effect of (quality) marital life on mental health outcomes. ${ }^{14}$

Regarding the types of social participation/experience which were analyzed, only that of joining community activities was found to be associated with depression and loss of interest in pleasurable activities. From the analysis, it is hard to contextualize this distinctive role of the ability to engage in community activities, as no clear definition was available on the type of activities or the level of participation in such activities. However, it is assumable that people with greater adherence to community activities also enjoy a greater exposure to recreational and companionship opportunities. A longitudinal study on elderly men and women in America (National Health and Aging Trend Study) reported that perceived cohesion and frequency of going out were directly associated with depressive symptoms in the population. ${ }^{15}$ Similar findings were replicated in adult samples as potential barriers to engagement in community activities (eg, social disorder and violence) and lower levels of social cohesion were associated with poorer mental health status. ${ }^{16}$

The findings of the present study provide important insight for geriatric nursing in South Africa. Improved socioeconomic status, health care services, and rising HIV survival rates (higher coverage of antiretroviral therapy) mean that a larger proportion of the population can expect to live longer and thus can experience higher prevalence of chronic noncommunicable diseases including depression. ${ }^{17,18}$ Hence, ensuring the provision of societal conditions for healthy ageing is imperative for social policy makers and health care systems. In order to achieve this, a better synergy between health and social researchers is required to explore the barriers to social participation among the elderly population who are in greater need of social support and care.

In addition to the findings, there are some strengths and limitations of the study which need to be discussed. This is the first study to explore the association between difficulties in social engagement and depression outcomes among the elderly population in South Africa. One important limitation of this study was the lack of generalizability of the study sample, as the sample was not representative of the population. However, the paper is an important contribution to the current literature, and hopefully sets the stage for future developments of this theme in South Africa or countries with a similar level of demographic and social transition. The study being cross-sectional meant that no causal relationship can be established between the outcome and explanatory variables, neither can it provide any information on the directionality of the relationship. We also could not adjust the analysis for some other important confounders due to the secondary nature of the data. Last but not least, the variables were self-reported and thus remain subject to reporting bias.

\section{Conclusion}

In conclusion, the results indicated a considerably high prevalence of depression in the sample population. Difficulty engaging in community activities was associated with significantly higher odds of perceived depression and loss of interest in pleasurable activities among the subjects. Noticeable differences were also observed in the prevalence rates among men and women. Intervention policies are therefore suggested to focus on addressing the barriers to community participation among older individuals, keeping the sex issues in focus. It is important to note that this study was limited in its scope on exploring the association between social participation and self-perceived depression only, and provides no evidence on the factors which hinder social participation. Further studies are therefore necessary to fill the knowledge gaps, and assist in informed social and health policy making targeting mental health outcomes among the older population.

\section{Acknowledgments}

The authors would like to acknowledge the generous provision of the datasets by WHO. This study is supported by the Science and Technology Department of Guizhou Province "The service package research and survey for elderly in pension institutions of Zunyi City".

\section{Disclosure}

The authors report no conflicts of interest in this work.

\section{References}

1. Piškur B, Daniëls R, Jongmans MJ, et al. Participation and social participation: are they distinct concepts? Clin Rehabil. 2014;28(3):211-220.

2. Goll JC, Charlesworth G, Scior K, Stott J. Barriers to social participation among lonely older adults: the influence of social fears and identity. Plos One. 2015;10(2):e0116664.

3. Guillen L, Lluis C, Saris WE. Measurement of social participation and its place in social capital theory. Social Indicators Res. 2011;100(2): 331-350.

4. Kanamori S, Kai Y, Aida J, et al. Social participation and the prevention of functional disability in older Japanese: the JAGES cohort study. Plos One. 2014;9(6):e99638.

5. Williamson L. Patient and citizen participation in health: the need for improved ethical support. Am J Bioeth. 2014;14(6):4-16.

6. Tong HM, Daniel WL, Zeng Q, Xu WY. Effects of social exclusion on depressive symptoms: elderly Chinese living alone in Shanghai, China. J Cross Cult Gerontol. 2011;26(4):349-364.

7. Meyer RP, Schuyler D. Old age and loneliness. Prim Care Companion CNS Disord. 2011;13(2):e1-e2.

8. Singh A, Misra N. Loneliness, depression and sociability in old age. Ind Psychiatry J. 2009;18(1):51-55.

9. Fiske A, Wetherell JL, Gatz M. Depression in older adults. Annu Rev Clin Psychol. 2009;5:363-389. 
10. World Health Organization. South Africa-SAGE Well-Being of Older People Study-2010, Wave 1. Geneva: World Health Organization; 2012. Available from: http://apps.who.int/healthinfo/systems/surveydata/ index.php/catalog/7/related_citations. Accessed May 29, 2017.

11. Nyirenda M, Chatterji S, Falkingham J, et al. An investigation of factors associated with the health and well-being of HIV-infected or HIV-affected older people in rural South Africa. BMC Public Health. 2012; 12:259.

12. Albert PR. Why is depression more prevalent in women? J Psychiatry Neurosci. 2015;40(4):219-221.

13. Bulloch AG, Williams JV, Lavorato DH, Patten SB. The relationship between major depression and marital disruption is bidirectional. Depress Anxiety. 2009;26(12):1172-1177.

14. Nilsson PM, Nilsson JA, Ostergren PO, Berglund G. Social mobility, marital status, and mortality risk in an adult life course perspective: the Malmö Preventive Project. Scand J Public Health. 2005;33(6): $412-423$.
15. Choi NG, Kim J, DiNitto DM, Marti CN. Perceived social cohesion, frequency of going out, and depressive symptoms in older adults. Gerontol Geriatr Med. 2015;1:2333721415615478.

16. De Silva MJ, McKenzie K, Harpham T, Huttly SR. Social capital and mental illness: a systematic review. J Epidemiol Community Health. 2005;59(8):619-627.

17. Xavier Gómez-Olivé F, Thorogood M, Clark BD, Kahn K, Tollman SM. Assessing health and well-being among older people in rural South Africa. Glob Health Action. 2010;3:23-35.

18. Kahn K, Garenne ML, Collinson MA, Tollman SM. Mortality trends in a new South Africa: hard to make a fresh start. Scand J Public Health Suppl. 2007;69:26-34.
Clinical Interventions in Aging

\section{Publish your work in this journal}

Clinical Interventions in Aging is an international, peer-reviewed journal focusing on evidence-based reports on the value or lack thereof of treatments intended to prevent or delay the onset of maladaptive correlates of aging in human beings. This journal is indexed on PubMed Central, MedLine,

\section{Dovepress}

CAS, Scopus and the Elsevier Bibliographic databases. The manuscript management system is completely online and includes a very quick and fair peer-review system, which is all easy to use. Visit http://www.dovepress. com/testimonials.php to read real quotes from published authors. 